\title{
Caregivers' Knowledge on Routine Growth Monitoring of Children Aged 9 Months in Nyamira County, Kenya
}

\author{
Justus O. S. Osero \\ Department of Community Health and Epidemiology, School of Public Health and Applied Human Sciences, \\ Kenyatta University, P.O. Box 43844, 00100 Nairobi, Kenya
}

DOI: $10.7176 / \mathrm{JHMN} / 72-05$

Publication date:March $31^{\text {st }} 2020$

\begin{abstract}
1. Introduction
Growth monitoring is one of the services offered in Maternal Neonatal and Child Health (MNCH) Clinics in health facilities encompassing routine check-ups by health workers to examine whether a child is growing as expected. Other services provided in these clinics are not limited to; vitamin A supplementation, immunization, health education and counselling, minor ailment treatment, screening for nutritional and medical conditions for management and defaulter tracing and follow-ups (Debuo et al. 2017). Measuring the weight and length of children monthly reflects their growth pattern which is compared against WHO's growth standards to ascertain whether a child is growing consistently, showing a growth concern or trending towards a growth problem that need to be addressed. A study conducted in Southern Ethiopia found out that $53 \%$ of the caregivers had poor knowledge on growth monitoring (Daniel et al. 2017). Majority of them said they did not know what a growth chart entailed nor did they know how to interpret growth curves (Daniel et al. 2017). A study conducted in Ghana revealed that more than $40 \%$ of the caregivers lacked good knowledge on routine growth monitoring. This study found out that more than $30 \%$ of the caregivers did not understand the meaning of routine growth monitoring and only $18.7 \%$ of them were able to interpret the normal, static, upward and decline growth curves (Debuo et al. 2017). A study in Zambia established that majority (92\%) of the caregivers of children aged between 0-59 months had knowledge on the importance of growth monitoring (Banda, 2012). Caregivers of children aged between 12-23 months in Zambia and Ethiopia were reported to have poor knowledge on feeding practices (Bilal et al. 2014, Banda, 2012). Daniel et al. (2014), Elana et al. (2009) and Roberfroid et al. (2005) found out that more than half of the caregivers were unable to understand and interpret the growth charts. Low comprehension on growth charts implies that healthcare providers do not educate caregivers using the growth chart (Gyampoh, 2012).
\end{abstract}

\section{Materials and Methods}

This was a cross-sectional study conducted in six health facilities in Kenya. The study was conducted for two months between December 2018 and February 2019.

\subsection{Study Location}

This study was conducted in Nyamira County which is one of the 47 County Governments in the Republic of Kenya created under the first schedule of the Constitution of Kenya 2010. Nyamira County is in Nyanza region of Kenya. It lies on the latitude $0^{\circ} 44^{\prime} 59.99^{\prime \prime} \mathrm{N}$ and longitude: $35^{\circ} 00^{\prime} 0.00^{\prime \prime} \mathrm{E}$. The study was done in six health facilities namely: Nyamira County Referral Hospital, Ekerenyo, Nyamusi, Borabu and Masaba Sub-County Hospitals and Ting'a Health Centre.

\subsection{Target and Study Population}

The target population for the study involved children aged 9 months. Caregivers of children aged 9 months in health facilities in Nyamira County and key informants formed the study population.

\subsection{Sampling Procedure}

Nyamira County was chosen purposively because it had the study characteristics just like any other county in Kenya. Health facilities for the study were selected using purposive sampling based on high volume of children population. Caregivers of children aged 9 months were selected using purposive sampling since beyond nine months they rarely take their children for RGM. Caregivers who took part in the research were selected during study days as they visited Maternal Neonatal and Child Health $(\mathrm{MNCH})$ clinics until the sample size was attained.

\subsection{Data Collection instruments}

Questionnaires with both closed and open ended questions and key informant interview guide were used to obtain information from the respondents. 


\subsection{Methods of data collection}

The study recruited six Research Assistants (RA) who helped in administering the questionnaires to the Respondents. These RAs received adequate training on data collection from the study prior to engaging in the study. Close supervision of the RAs was done throughout the study by the PI to ensure accuracy of data collection process. During the data collection period, the research team introduced themselves and explained the purpose of the study to the respondents in a clear, open and honest manner. Caregivers who consented to the study were guided by the research team in filling the questionnaires. The research team also recorded information that was given by the key informants. These tools were written in English and administration took about 25 minutes and 30 minutes respectively.

\subsection{Ethical Considerations}

Approval to conduct the study was obtained from Kenyatta University Graduate School. Ethical clearance was obtained from Kenyatta University Ethics and Review Committee. Research permit was sought from national commission for science, technology and innovation (NACOSTI). Further approval was sought from ethics and review committee in Nyamira County. The study sought informed consent from the respondents before proceeding with the research.

\subsection{Data Analysis}

Statistical package for social sciences (SPSS) version 23 was used for the analysis of the quantitative data collected and chi-square test was used to test the association between the dependent and independent variables and the association was deemed significant when $p$ value was less than 0.05 at $95 \%$ confidence level. Content analysis was done for qualitative data and similar categories of data arranged into sub-themes and themes. Results were then presented as narrations or direct quotes which were then triangulated with the quantitative data.

\section{Results}

\subsection{Socio-demographic and Economic Characteristics of the Study Participants} Table 1: Caregivers' age $(\mathbf{n}=\mathbf{1 8 0})$

\begin{tabular}{|l|c|}
\hline Variable & Count \\
\hline Age (years) & 26 \\
\hline Mean & 26 \\
\hline Mode & 15 \\
\hline Minimum & 38 \\
\hline Maximum & \\
\hline
\end{tabular}

The study results revealed that the general mean age of the caregivers was 26 years, minimum age 15 years while maximum age was 38 years with majority of them aged 26 years (Table 1 ). 
Table 2: Socio-demographic and Economic Characteristics of the Study Participants (n=180)

\begin{tabular}{|c|c|c|}
\hline Variable & Frequency & Percentage (\%) \\
\hline \multicolumn{3}{|l|}{ Gender } \\
\hline Female & 180 & 100 \\
\hline \multicolumn{3}{|l|}{ Education level } \\
\hline Primary & 66 & 36.7 \\
\hline Secondary & 78 & 43.3 \\
\hline Tertiary/College & 36 & 20 \\
\hline \multicolumn{3}{|l|}{ Marital status } \\
\hline Single & 21 & 11.7 \\
\hline Married & 159 & 88.3 \\
\hline \multicolumn{3}{|l|}{ Occupation } \\
\hline Peasant Farmer & 69 & 38.3 \\
\hline Housewife & 70 & 38.9 \\
\hline Business person & 29 & 16.1 \\
\hline Employed & 12 & 6.7 \\
\hline \multicolumn{3}{|c|}{ Monthly Income (Kshs) } \\
\hline Less than 5000 & 78 & 43.3 \\
\hline $5000-10000$ & 21 & 11.7 \\
\hline Above 10000 & 15 & 8.3 \\
\hline None & 67 & 37.2 \\
\hline \multicolumn{3}{|l|}{ Gender of child } \\
\hline Female & 91 & 50.6 \\
\hline Male & 89 & 49.4 \\
\hline
\end{tabular}

Study results showed that $100 \%$ of the caregivers were female (Table 2 ). More than $80 \%$ of the caregivers were married (Table 2). The study results showed that $38.9 \%$ of the caregivers were housewives, $38.3 \%$ peasant farmers, $16.1 \%$ business persons and $6.7 \%$ employed (Table 2 ). About $43.3 \%$ of the caregivers earned a monthly income of less than KSh. 5000 and $37.2 \%$ of them were dependents (Table 2). About 50.6\% of the children were female and $49.4 \%$ male (Table 2 ).

\subsection{Meaning of Routine Growth Monitoring (RGM)}

\section{Caregivers' knowledge on meaning of RGM}

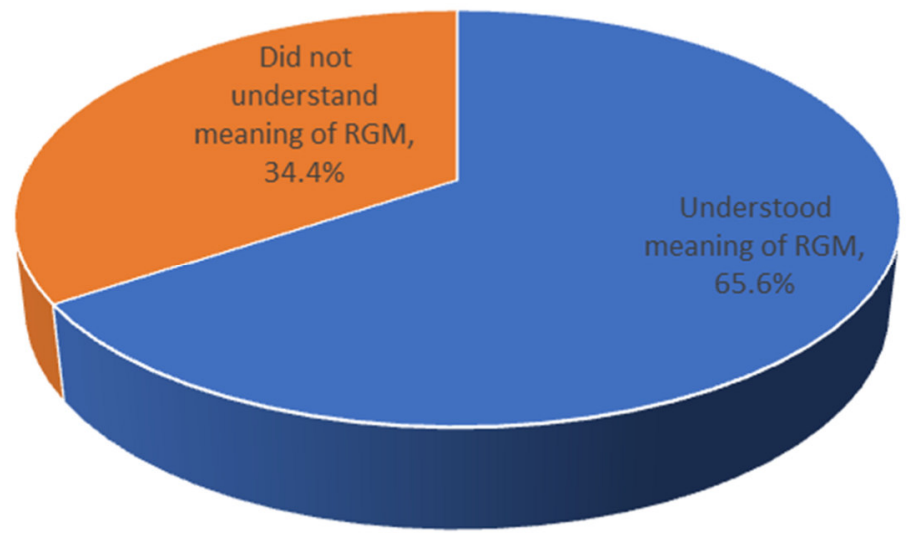

Figure 1: Proportion of Caregivers' who understood the meaning of RGM

Results of the study revealed that $118(65.6 \%)$ of the caregivers knew the meaning of RGM while $62(34.4 \%)$ did not understand its meaning. The caregivers who understood the meaning of RGM defined it correctly as regular measurement of a child's size in terms of height, weight and head circumference to ensure normality in growth.

One of the Nurses in one of the facilities said "Regular growth monitoring is that consistent measurement of 
children below 5 years of their height, weight and head circumference to ensure normalcy in growth". Another male Nurse Said, "You will be able to tell of their malnutrition and health issues". Head nurse in one of the facilities said that, "it must be regular meaning every month for children who are below five years"

Table 3: Association between socio-demographic and economic characteristics of the study participants and knowledge on the meaning of RGM

\begin{tabular}{|c|c|c|c|c|}
\hline \multirow{2}{*}{\multicolumn{2}{|c|}{ Variable }} & \multicolumn{2}{|c|}{ Meaning of RGM } & \multirow[b]{2}{*}{ Significance } \\
\hline & & \multirow{2}{*}{$\begin{array}{l}\text { Yes } \\
2(1.7 \%)\end{array}$} & \multirow{2}{*}{$\frac{\text { No }}{2(3.2 \%)}$} & \\
\hline \multirow[t]{6}{*}{ Age (Years) } & Below 18 & & & \multirow{6}{*}{$\mathrm{p}=0.897^{*}$} \\
\hline & $18-22$ & $24(20.3 \%)$ & $14(22.6 \%)$ & \\
\hline & $23-27$ & $44(37.3 \%)$ & $23(37.3 \%)$ & \\
\hline & $28-32$ & $32(27.1 \%)$ & $17(27.4 \%)$ & \\
\hline & $33-37$ & $13(11.1 \%)$ & $6(9.7 \%)$ & \\
\hline & $38-42$ & $3(2.5 \%)$ & $0(0 \%)$ & \\
\hline \multirow[t]{2}{*}{ Marital status } & Married & $105(89.2 \%)$ & $54(87.1 \%)$ & \multirow[b]{2}{*}{$\chi^{2}=0.140 ; \mathrm{df}=1 ; \mathrm{p}=0.708$} \\
\hline & Single & $13(1.1 \%)$ & $8(12.9 \%)$ & \\
\hline \multirow[t]{3}{*}{ Education level } & Primary & $27(22.9 \%)$ & $38(61.3 \%)$ & \multirow{3}{*}{$\chi^{2}=29.238 ; \mathrm{df}=4 ; \mathrm{p}<0.001$} \\
\hline & Secondary & $61(51.7 \%)$ & $17(27.4 \%)$ & \\
\hline & Tertiary & $18(15.3 \%)$ & $7(11.3 \%)$ & \\
\hline \multirow[t]{4}{*}{ Occupation } & Peasant Farmer & $36(30.5 \%)$ & $33(53.2 \%)$ & \multirow{4}{*}{$\mathrm{p}=0.003^{*}$} \\
\hline & Housewife & $47(39.8 \%)$ & $23(37.1 \%)$ & \\
\hline & Self-employed & $23(19.5 \%)$ & $6(9.7 \%)$ & \\
\hline & Employed & $12(10.2 \%)$ & $0(0 \%)$ & \\
\hline \multirow{4}{*}{$\begin{array}{l}\text { Monthly } \\
\text { Income }\end{array}$} & $<5000$ & $42(35.6 \%)$ & $35(36.5 \%)$ & \multirow{4}{*}{$\mathrm{p}=0.015^{*}$} \\
\hline & $5000-10000$ & $15(12.7 \%)$ & $6(9.7 \%)$ & \\
\hline & 10000 and above & $14(11.9 \%)$ & $1(1.6 \%)$ & \\
\hline & Dependant/None & $47(39.2 \%)$ & $20(32.3 \%)$ & \\
\hline \multirow{2}{*}{$\begin{array}{l}\text { Gender of } \\
\text { child }\end{array}$} & Male & $59(50 \%)$ & $30(48.4 \%)$ & \multirow[b]{2}{*}{$\chi^{2}=0.142 ; \mathrm{df}=1 ; p=0.837$} \\
\hline & Female & $59(50 \%)$ & $32(51.6 \%)$ & \\
\hline \multirow[t]{2}{*}{ Residence } & Urban & $51(43.1 \%)$ & $15(24.2 \%)$ & \multirow[b]{2}{*}{$\chi^{2}=6.332 ; \mathrm{df}=1 ; \mathrm{p}=0.012$} \\
\hline & Rural & $67(56.8 \%)$ & $47(75.8 \%)$ & \\
\hline
\end{tabular}

\section{Key: Fishers' Exact test}

Analysis of results on caregivers' knowledge on the meaning of RGM showed a significant relationship with level of education $\left(\chi^{2}=29.238 ; \mathrm{df}=4 ; \mathrm{p}<0.0001\right)$, occupation $(\mathrm{p}=0.001)$, monthly income $(\mathrm{p}=0.015)$, residence $\left(\chi^{2}=6.332 ; \mathrm{df}=1 ; \mathrm{p}=0.012\right)$ (Table 3$)$. Further, there was no significant association between caregivers' knowledge on meaning of RGM and their age $(\mathrm{p}=0.897)$, marital status $\left(\chi^{2}=0.140 ; \mathrm{df}=1 ; \mathrm{p}=0.708\right)$ as well as gender of their children $\left(\chi^{2}=0.142 ; \mathrm{df}=1 ; \mathrm{p}=0.837\right)$ (Table 3$)$.

\subsection{Caregivers' Knowledge on when Children should be taken for RGM}

The study showed that $59(50 \%)$ of caregivers knew that children should be taken for RGM during immunization, 57 (48.3\%) monthly, 32 (27.1\%) when child is sick. (Table 4).

Table 4: Proportion of caregivers with knowledge on when children should be taken for RGM

\begin{tabular}{|l|l|l|}
\hline Variable & Yes & No \\
\hline During immunization & $59(50 \%)$ & $59(50 \%)$ \\
\hline Monthly & $57(48.3 \%)$ & $61(51.7 \%)$ \\
\hline When sick & $32(27.1 \%)$ & $86(72.9 \%)$ \\
\hline
\end{tabular}

A Nurse in one of the health facilities said "once a caregiver comes to the clinic for the first time, we inform her when to come next." "First time caregivers have little understanding as to when they should take their babies for regular growth monitoring clinic" said a Nurse at the MNCH clinic. 


\subsection{Knowledge on what is done during RGM visit}

Table 5: Caregivers' knowledge on what is done to children aged 9 months during RGM

\begin{tabular}{|l|l|l|}
\hline Variable & Yes & No \\
\hline Weight measured & $118(100 \%)$ & $0(0 \%)$ \\
\hline Height measured & $116(98.3 \%)$ & $2(1.7 \%)$ \\
\hline Detection of malnutrition & $19(16.1 \%)$ & $99(83.9 \%)$ \\
\hline Detection of poor health & $15(12.7 \%)$ & $103(87.3 \%)$ \\
\hline Taught hygiene practices & $6(9.5 \%)$ & $112(94.9 \%)$ \\
\hline Taught feeding practices & $6(9.5 \%)$ & $112(94.9 \%)$ \\
\hline Child vaccination & $6(9.5 \%)$ & $112(94.9 \%)$ \\
\hline Head circumference measured & $5(4.2 \%)$ & $113(95.8 \%)$ \\
\hline Taught signs of abnormality in children & $4(3.4 \%)$ & $114(96.6 \%)$ \\
\hline Taught signs of sickness in children & $4(3.4 \%)$ & $114(96.6 \%)$ \\
\hline Vitamin A supplementation & $4(3.4 \%)$ & $114(96.6 \%)$ \\
\hline Taught home remedy for sick child & $2(1.7 \%)$ & $116(98.3 \%)$ \\
\hline
\end{tabular}

Caregivers were interviewed to establish their knowledge on what is exactly done at $\mathrm{MNCH}$ clinic during RGM Visit. Analysis of the study results revealed that $118(100 \%)$ of the caregivers knew that weight of children is measured during RGM. Other activities mentioned by caregivers done during RGM visit included; measurements of children's height 116 (98.3\%), detection of malnutrition 19 (16.1\%) among others (Table 5). It is clear from the study that majority of the caregivers didn't know that vitamin A and other child vaccines were provided during RGM visits and especially after 9 months.

"Child's height, weight and head circumference are very basic measurements done at the MNCH clinics when children are brought for growth monitoring and immunization", said one of the nurses. "Mothers are taught on how to feed their child to avoid under nutrition. Vitamin A is every time given to the child when brought for growth monitoring" another nurse in said.

\subsection{Knowledge on benefits of RGM}

\section{Caregivers' knowledge on benefits of RGM}

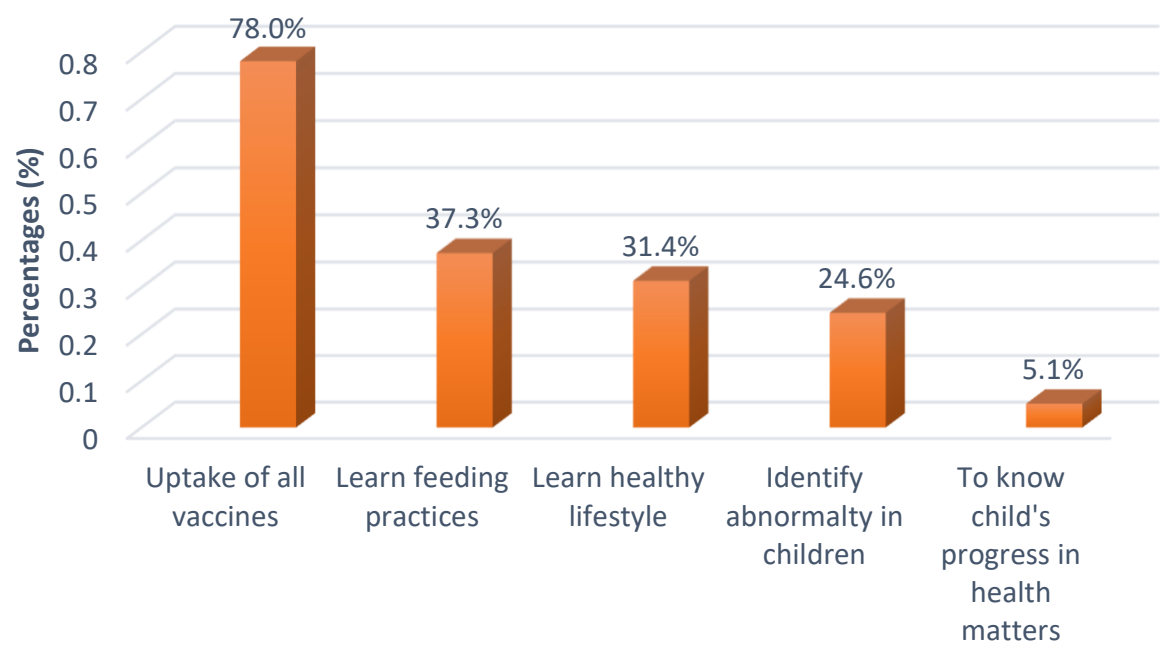

Benefits of RGM

Figure 2: Caregivers' knowledge on benefits of RGM

The caregivers were interviewed to establish whether they understand the benefits of RGM to the children. Results of the study showed that $92(78 \%)$ of caregivers reported uptake of all vaccines for children as the major benefit of RGM (Figure 2). Other benefits of RGM mentioned by caregivers included; that it enabled them to learn feeding practices 44 (37.3\%), healthy lifestyle 37 (31.4\%) among other benefits (Figure 2).

In-charge Nurse of MNCH clinic in one of the health facilities said "the benefits of regular growth monitoring doesn't only involve uptake of all vaccines but also the caregivers get to know health matters of the child, good health lifestyle, able to identify abnormality in children and learn feeding practices." Another Nurse in one of the Facilities asserted that, "some of the caregivers don't understand the benefits routine growth monitoring". "These caregivers need to be told every now and then the benefits of regular growth monitoring" said one of the health 
care providers at one of the $\mathrm{MNCH}$ clinics.

\subsection{Caregivers' Knowledge on Meaning of a Child Health Card or Book}

\section{Caregivers' knowledge on meaning of a child health card}

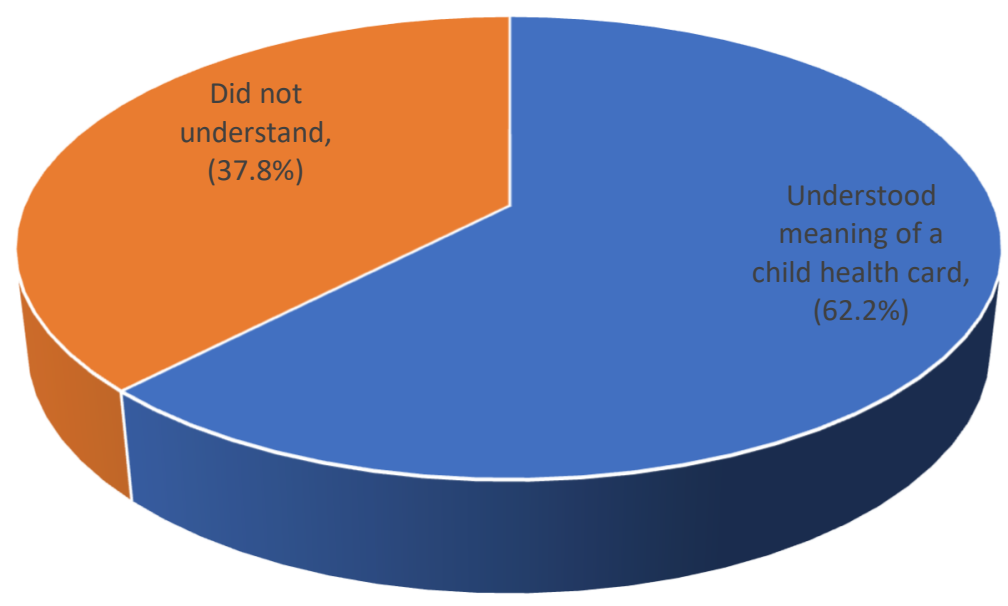

Figure 3: Caregivers' knowledge on meaning of a child health card

The study showed $112(62.2 \%)$ of the caregivers had knowledge on meaning of a child health card or book while $68(37.8 \%$ ) did not the meaning (Figure 3$)$. Those caregivers who knew the meaning all defined it correctly as a document that contains clinic details including name, age, date of birth among other details for a particular child.

\subsection{Caregivers' knowledge on the Information in a child health card or book}

Table 6: Caregivers' knowledge on the information in a Child health card/book

\begin{tabular}{|l|l|l|}
\hline Variable & Yes & No \\
\hline Weight-for-age & $103(92 \%)$ & $9(8 \% \%)$ \\
\hline Height-for-age & $100(89.3 \%)$ & $12(10.7 \%)$ \\
\hline To Come Again (TCA) & $89(79.5 \%)$ & $23(20.5 \%)$ \\
\hline Recommended vaccine schedule & $70(62.5 \%)$ & $42(37.5 \%)$ \\
\hline Feeding recommendation guide & $48(42.9 \%)$ & $64(57.1 \%)$ \\
\hline Bio-data & $51(45.5 \%)$ & $61(54,5 \%)$ \\
\hline Vitamin A supplementation schedule & $28(25 \%)$ & $84(75 \%)$ \\
\hline Paediatric assessment notes/information & $25(22.3 \%)$ & $87(77.7 \%)$ \\
\hline Head circumference & $14(12.5 \%)$ & $98(87.5 \%)$ \\
\hline Milestone assessment & $13(11.6 \%)$ & $99(88.4 \%)$ \\
\hline HIV prophylaxis schedule & $6(5.4 \%)$ & $106(94.6 \%)$ \\
\hline Body Mass Index (BMI)-for-age & $5(4.5 \%)$ & $107(95.5 \%)$ \\
\hline Ways of creating bond between mother and child & $3(2.7 \%)$ & $109(97.3 \% \%)$ \\
\hline Family planning information for the mother & $2(1.8 \%)$ & $110(98.2 \%)$ \\
\hline
\end{tabular}

The study found out that caregivers were aware of various information contained in a child health card including weight-for-age 103 (92\%), height-for-age 100 (89.3\%), Clinic appointment date \{To Come Again (TCA)\} $89(79.5 \%)$ among other information (Table 6).

In interviewing health care provider as key informants, one of them said "most caregivers carry child health cards with them whenever they visit the clinic but they rarely know the content and importance of it. "Another said that "there is need for regularly educating mothers on the information and significance of child card". "Some of the caregivers don't know how to read and even interpret what is in the card but then we every time try to inform them" said another health care provider in $\mathrm{MNCH}$ clinic of one of the facilities. 


\subsection{Caregivers' Knowledge on the Meaning of a Growth Monitoring Curve (GMC)}

\section{Caregivers' knowledge on a GMC}

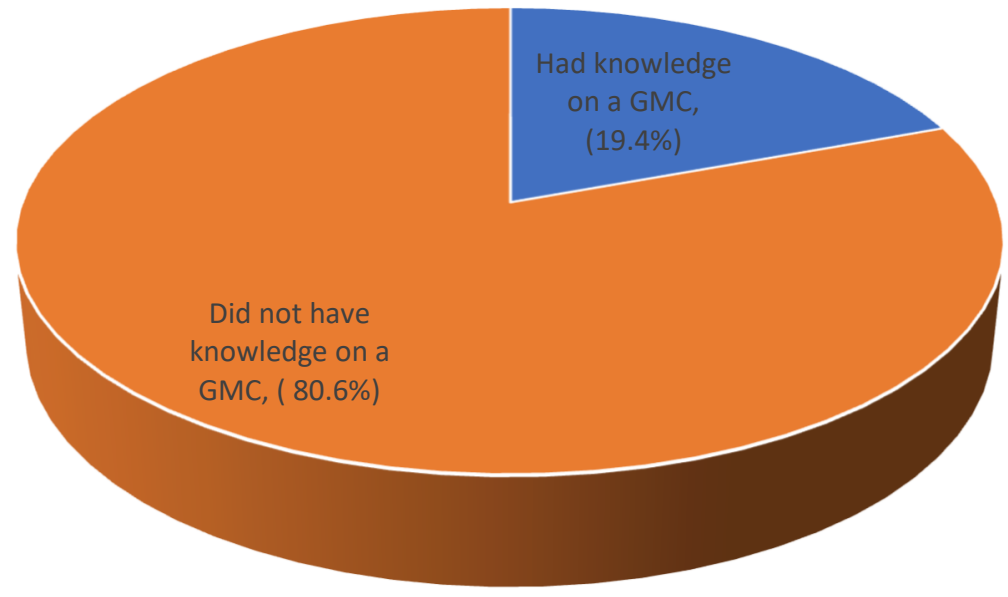

Figure 4: Caregivers' knowledge on the meaning of a growth monitoring chart

Results of the study showed that only $35(19.4 \%)$ of the caregivers understood the meaning of a growth monitoring chart while 145 (80.6\%) did not know its meaning (Figure 4). Those who knew correctly defined it as a curve showing a child's height and weight in a period of time.

"Majority of the caregivers don't know the meaning of growth monitoring curve, they can't even read and interpret it" said Head nurses of all the health facilities involved in this study. Almost all the health care providers interviewed for key information pointed out that "Nurses don't bother to train caregiver on the meaning of growth monitoring card nor to assist them interpret the curve, they are only told whether the child is doing good or bad then the follow up date."

\subsection{Caregivers' knowledge on interpretation of a Growth Monitoring Curve (GMC)}

\section{Caregivers' knowledge on interpretation of a GMC}

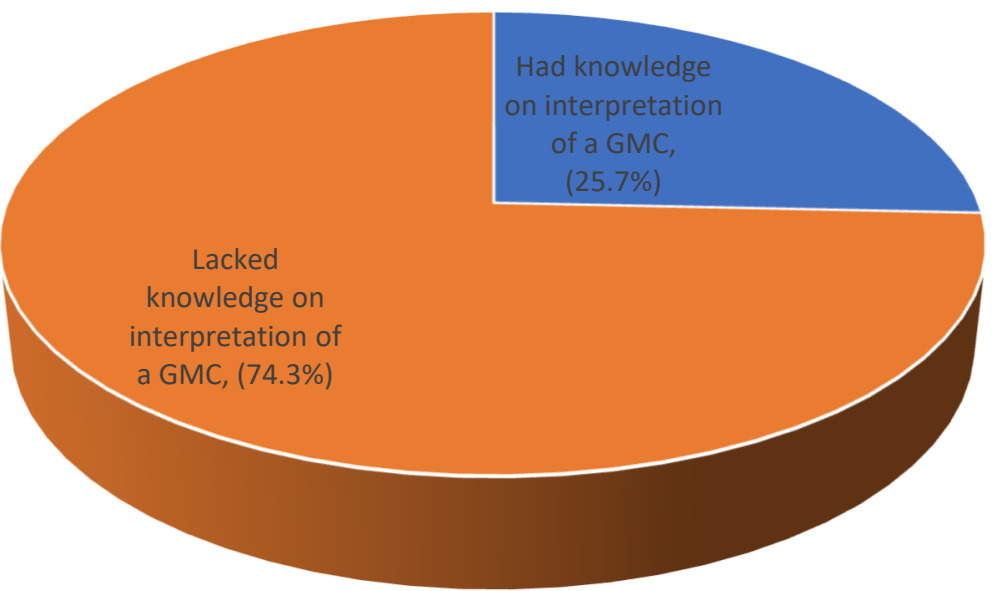

Figure 5: Caregivers' knowledge on interpretation of a GMC 
Analysis of the study results showed that only 9 (25.7\%) of the caregivers had knowledge on interpretation of a GMC (Figure 5). When these caregivers were asked of source of their knowledge on interpretation of GMC, $8(88.9 \%)$ of them said that it was by self-knowledge (Table 7$)$. The study found out that $26(74.3 \%)$ indicated that they did not know how to interpret a growth monitoring curve. Among them, $18(69.2 \%)$ reported that their healthcare providers had never taught them on how to interpret a GMC (Table 7).

Table 7: Caregivers' sources of knowledge on interpretation and reasons for lack of knowledge on interpretation of a GMC

\begin{tabular}{|l|l|}
\hline Variable & \multicolumn{1}{|l|}{ Percentage (\%) } \\
\hline Sources of knowledge on interpretation of a GMC (n=9) \\
\hline Self-knowledge & $8(88.8 \%)$ \\
\hline Taught by Healthcare provider & $1(11.2 \%)$ \\
\hline Reasons for caregivers' lack of knowledge on interpretation of a GMC (n=26) \\
\hline Never been taught by Healthcare provider & $18(69.2 \%)$ \\
\hline Never seen it & $8(30.8 \%)$ \\
\hline
\end{tabular}

3.10 Caregivers' knowledge on health problems likely to be encountered out of failure to attend RGM

Caregivers' knowledge on health problems likely to be encountered out of falure to attend RGM

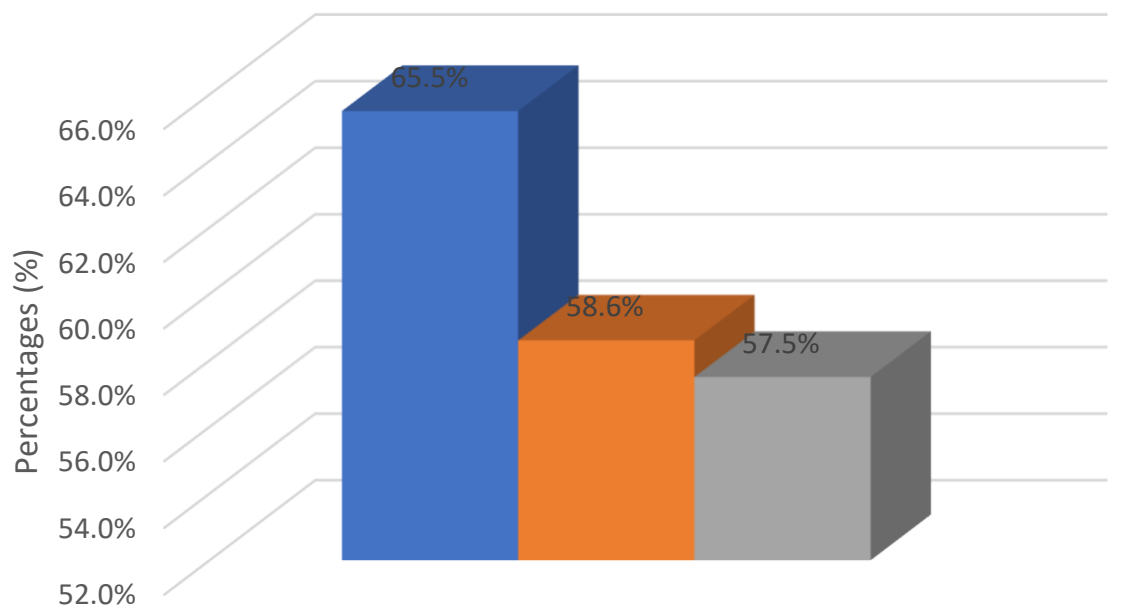

Health Problems

- Measles Disease $\square$ MalnourishmPent $\quad$ Poliomyelitis Disease

Figure 6: Caregivers' knowledge on health problems likely to be encountered out of failure to attend RGM

The study results revealed that $87(77.7 \%)$ of the caregivers mentioned that there is a likelihood of developing health problems among children not taken for RGM while only $25(22.3 \%)$ of them said that children may not encounter any health problems as a result of not attending RGM. Various health problems likely to be encountered which were reported by the caregivers include measles disease $57(65.5 \%)$, malnourishment 51(58.6\%) and poliomyelitis disease $50(57.5 \%)$ (Figure 6).

"Most caregivers discontinue regular growth monitoring activities after 9 months because they don't understand of it after the $9^{\text {th }}$ month. They don't even know of the many health problems children encounter once they discontinue regular growth monitoring after 9 months" said Head Nurse of one of the health facilities.

\section{Discussion}

\subsection{Socio-demographic and Economic Characteristics of the Study Participants}

The study found out that most of the caregivers were aged between 26 years old. This result is consistent to a similar study done in Ghana by Debuo et al., (2017) which realized that more than half (53.7\%) of the caregivers of the children were aged between 26 to 35 years. A study by Woke (2013) in Ethiopia also revealed that many $(73 \%)$ of the caregivers was in the age group of 20 to 35 years.

Results of the study revealed that all the caregivers were female and biological mothers of the children. This concurs to a study done in Uganda by Debuo et al., (2017) in which over 93.7\% of the caregivers were biological 
mothers of the children. A similar other study by Mwari et al., (2017) also found out that many (94\%) of the caregivers were mothers of the children.

The study showed that majority (more than $80 \%$ ) of the caregivers were married. This is in agreement to another study done in Ethiopia by Daniel et al., (2017) which found out that $89.3 \%$ of the caregivers of children were married.

According to the findings of the study, most of the caregivers had secondary level of education. In her presentation, Nyabuti (2015) reported that many (63.7\%) of the caregivers of children who attended RGM in Kenya had secondary level of education. High levels of literacy mean better health seeking behaviour since caregivers understand the importance of RGM.

Findings of the study revealed that many of the caregivers were either peasant farmers or housewives. This agrees to another study conducted in Ethiopia by Bilal et al., (2014) which found out that most (88\%) of the caregivers of children were farmers. However, this is inconsistent to a similar other study done in Kenya by Nyabuti (2015) which found out that more than half (54.8\%) of the caregivers of the children were self-employed.

Study results showed that most of the caregivers earned a monthly income of less than Kshs 5000. This concurs to a study done in Ethiopia by Daniel et al., (2017) which reported that many of the caregivers earned a monthly income of between 500 to 1000 Birr (1575 to $3150 \mathrm{Kshs}$ ).

\subsection{Caregivers' Knowledge on RGM}

The study found out that $34.4 \%$ of the caregivers did not understand the meaning of RGM. This finding disagrees to the findings of a similar study conducted in Ghana by Debuo et al., (2017) which found out that more than 30\% of the caregivers did not understand the meaning of routine growth monitoring.

The study realized that only $25.7 \%$ of the caregivers had knowledge on interpretation of a GMC. This is inconsistent to the findings of a similar study conducted in Ethiopia by Daniel et al., (2017) which found out that about more than half $(62.1 \%)$ of the caregivers knew how to interpret a GMC. However, this result is agrees to the findings of a study conducted in Ghana which reported that only $18.7 \%$ of caregivers were able to interpret the normal, static, upward and decline growth curves (Debuo et al. 2017). The caregivers who knew how to interpret a GMC reported that their source of knowledge on interpretation of a GMC was self-knowledge. This result is in contrary to the findings of similar studies conducted in other countries whereby more than $77 \%$ of the caregivers revealed that Healthcare Providers (doctors and nurses) were the main sources of information regarding their children (Seskute et al., 2018, Kundi et al.,2015, Kennedy et al.,2011).

Findings of the study showed that about $48.3 \%$ of caregivers reported that children should be taken for RGM monthly. This contrasts the findings of another study conducted in Ethiopia whereby only $32.1 \%$ of caregivers reported that growth monitoring should be carried out monthly (Daniel et al., 2017)

From the analysis of study results, more than half of the study participants understood the importance of RGM. This result agrees to those of another similar study done in Zambia which reported that majority (92\%) of the caregivers of children had knowledge on the importance of growth monitoring (Banda, 2012).

Further analysis revealed that uptake of all vaccines was the main benefit of RGM. A study by Ashworth et al., (2008) found out that medications including vaccinations are more valued than preventive services such as nutrition counselling. Another study conducted in Ghana by Agbozo (2018) reported knowledge on child's growth status as the major benefit of attending RGM.

\section{Conclusion}

i) All the caregivers from were female and biological mothers of the children. Males or fathers should be enlightened to know they have a significant role when it comes to attending RGM for their children.

ii) More than $30 \%$ of the caregivers did not understand the meaning of RGM. This implies that caregivers of children should be regularly trained and reminded by HCP for them to understand RGM.

\section{Recommendation}

HCP especially those deployed in Child Welfare Clinics should ensure they have relevant and updated material on RGM for regular training of the caregivers. This will ensure all caregivers regardless of their socio-economic and demographic characteristics have equal knowledge on RGM at all times.

\section{Acknowledgement}

The study appreciates all persons who significantly contributed to the success of this research namely Kenyatta University, Nyamira County Government, Management of all health facilities, Research Assistants and all caregivers of children aged 9 months.

\section{References}

Debuo, D.T., Kubi, A.P., Kweku, M., Asalu, A.G., Ahiab, S.Y., Kwami, T.W., \& Duut, A.B. (2017). Caregivers' 
Knowledge, Attitude and Practices on Child Growth Monitoring and Promotion Activities in Lawra District, Upper West Region of Ghana. Science Journal of Public Health (5): 1

Daniel, B., Tesfaye, N., Mekonin, E., Kassa, A., \& Mensur, K. (2017). Knowledge and Attitude on Growth Monitoring and its Associated Factors among Mothers/Guardians of Children Less than Two Years in Areka Town, Southern Ethiopia. Journal of Nutritional Disorders \& Therapy (7): 216.

Banda, D. H. (2012). Incorporation of child survival strategies among mothers in Zambia: a knowledge, attitude and practice survey.

Bilal, S. M., Moser, A., Blanco, R., Spigt, M. \& Dinant, G. J. (2014). Practices and Challenges of Growth Monitoring and Promotion in Ethiopia: A Qualitative Study. Journal of Health, Population, and Nutrition, 32 (3): 441

Elana, P., Steven, A., \& Neil, I. (2009). Do Parents Understand Growth Charts? A National, Internet-Based Survey. Pediatrics 124(4)

Roberfroid, D., Kolsteren, P., Hoeree, T., \& Maire, B. (2005). Do growth monitoring and promotion programs answer the performance criteria of a screening program? A critical analysis based on a systematic review. Tropical Medicine and International Health (10)

Gyampoh, S. (2012). Assessment of Clinic-Based Growth Monitoring and Promotion in the Accra Metropolitan Area of Ghana. University of Ghana.

Mwari, L., Simbauni, J., \& Keraka, M. (2017). Care Giver Deteminants of Utilization of Growth Monitoring Clinic Among Children Aged 12-59 Months in Urban Kiambu County, Kenya. International Journal of Innovative Research and Advanced Studies (IJIRAS)4(6)

Nyabuti, I.J. (2015). Factors Associated with the Continuation of Growth Monitoring among Children 10-59 months in Nyamira County, Kenya.

Ashworth, A., Shrimpton, R., \& Jamil, K. (2008). Growth monitoring and promotion: review of evidence of impact Maternal \& Child Nutrition (4): 86-117.

Agbozo, F., Esi, C., Jahn, A., \& Timothy, G. (2018). Understanding why child welfare clinic attendance and growth of children in the nutrition surveillance programme is below target: lessons learnt from a mixed methods study in Ghana. BMC Nursing 17-25

Awoke, W., (2013). Prevalence of childhood illness and mothers'/caregivers' care seeking behavior in Bahir Dar, Ethiopia: A descriptive community-based cross sectional study. Open Journal of Preventive Medicine 3(2): 155-159.

Seskute, M., Egle, T., \& Giedra, L. (2018). Knowledge and Attitudes of Postpartum Mothers towards Immunization of their Children in a Lithuanian Tertiary Teaching Hospital. Medicina 54: 2

Kundi, M., Obermeier, P., Helfert, S., Oubari, H., Fitzinger, S., Yun, J.A., Brix, M., \& Rath, B. (2015). The Impact of Parent-Physician relationship on Parental Vaccine Safety Perceptions. Curr. Drug Saf. 10: 16-22.

Kennedy, A., Lavail, K., Nowak, G., Basket, M., \& Landry, S. (2011). Confidence about vaccines in the United States: Understanding parents' perceptions. Health Aff., 30:1151-1159 